Fournal of Medical Genetics (1972). 9, 316.

\title{
Dominant Ectrodactyly and Possible Germinal Mosaicism*
}

\author{
T. J. DAVID \\ From the Cardiac Department, General Hospital, Bristol
}

The split-foot or 'lobster claw' deformity is a form of congenital absence of one or more digits (ectrodactyly) affecting the central rays of the hand and foot. It can be sporadic or inherited, and although autosomal recessive cases are known (Freire-Maia, 1971) most inherited cases are due to an autosomal dominant gene. A notably careful survey of the literature by Vogel $(1957 / 1958)$ reveals that there are 2 types of dominant ectrodactyly.

In type 1 , the fundamental lesion is bilateral cleft foot, and the hands may be affected but never in the absence of the foot lesion (Lewis, 1909). Transmission is by an autosomal dominant gene, and skipping never occurs, ie, penetrance is $100 \%$.

In type 2 the lesion is much more variable. Some cases have typical cleft hands and feet, while others have only one deformed hand and normal feet. The most important feature is that the feet are not always affected. Transmission is again by an autosomal dominant gene, but skipping often occurs, and the expression of the gene is much more variable than in type 1. In this paper 3 new pedigrees of type 1 dominant ectrodactyly are reported, and germinal mosaicism may be a likely explanation in all 3 families.

\section{Families}

In all 3 families there is no known consanguinity and there are no affected members before the second generation. In the affected members all 4 limbs were affected in every case. All pedigrees (Figs. 1, 2, and 3, p. 317) are from the British Isles.

Family A (Fig. 1). All living members of the family were examined. In addition, palmar and plantar dermatoglyphs were recorded, photographs taken, and plaster and rubber casts made of all affected limbs. II.3 was not available and was thought to be in prison. II.5 though present declined to have his dermatoglyphs recorded. I.2 could confirm that her husband (I.1) was unaffected and that none of their predecessors were

\footnotetext{
Received 16 February 1972.

* First presented at the Institut für Humangenetik, Freiburg-imBreisgau, West Germany, 21 January 1972.
}

known to be affected. I. 2 is one of 11 children none of whom are affected.

The deformity in this family is identical in every affected case. It consists of quadrilateral monodactyly and a small bony protuberance over the medial malleolus. All affected members have 2 parallel metacarpals (Fig. 4), and in addition II.1, II.4, and III. 6 also have a 'crossbone' (Fig. 5) which is a bone running between the distal ends of the 2 parallel metacarpals. In generation II the first 2 sibs were affected and the 3 rd was normal.

Family B (Fig. 2). The following affected members were examined: III.7, IV.16, V.10, V.12, and VI.1. In addition, V.10 and VI.1 permitted photography. Details of the family tree were given by various family members, in particular III.7 and II.2. II.2 had photographs of II.1, II.3, and II.5 as well as of her parents-in-law (I.1 and I.2) and she was certain that there were no prese viously affected members.

The deformity in this family consisted of typical cleft feet and bilateral hand deformities which varied from a cleft hand with a single digit missing (VI.1) to simple monodactyly. In generation II the first 2 sibs were affected and the 2 subsequent sibs were normal.

Family C (Fig. 3). This family almost uniformly refused to allow the recording of dermatoglyphs or the taking of photographs, notable exceptions being III.13, IV.29 and IV.50, and V.22, V.44, V.45 (unaffected), and V.46. However they were prepared to help in confirming the family tree, and all the living affected members of generations IV and V were seen except IV.17, 42, 49, 52, 56,58 , and 67 , and V.50, 51, and 52 . The propositus was able to give almost the entire family tree from memory without a single mistake, leaving out the descendants of II.4 and II.5; a considerable feat. His information was independently confirmed by other relatives. Details of the family tree before generation III were given by III.3, III.13, and III.15 and in addition III. 3 had photographs of II.4, II.5, II.6, and her grandparents I.1 and I.2. Details of the deformity in II.8 were confirmed at the old people's home where he used to reside. III.19, III.20, III.21, and III.22, and their descendants could not be traced to be examined, but it was well known that III.21 and IV.67 were the only affected ones in these 2 lines of the family.

The deformity in this family consisted of monodactyly 

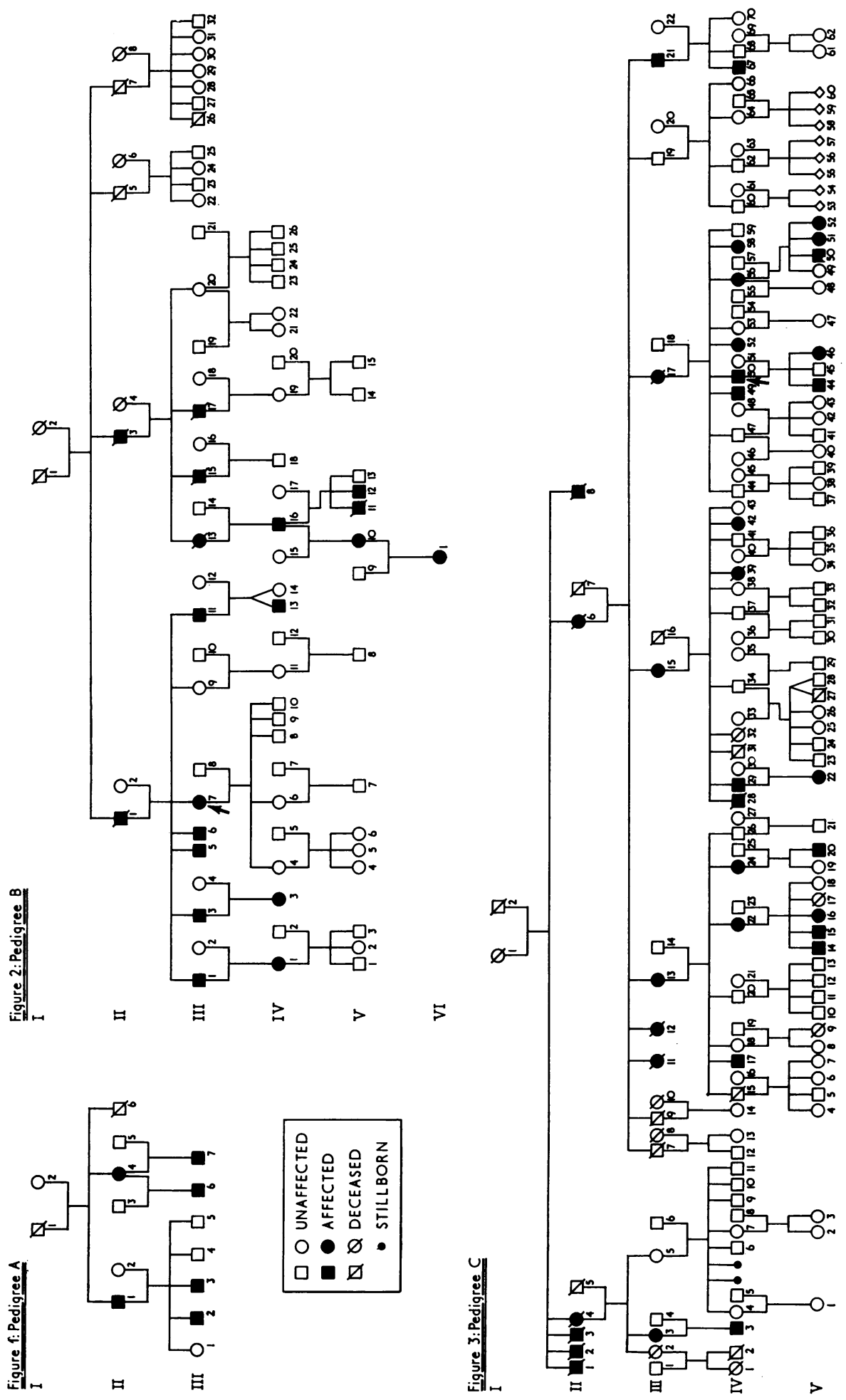

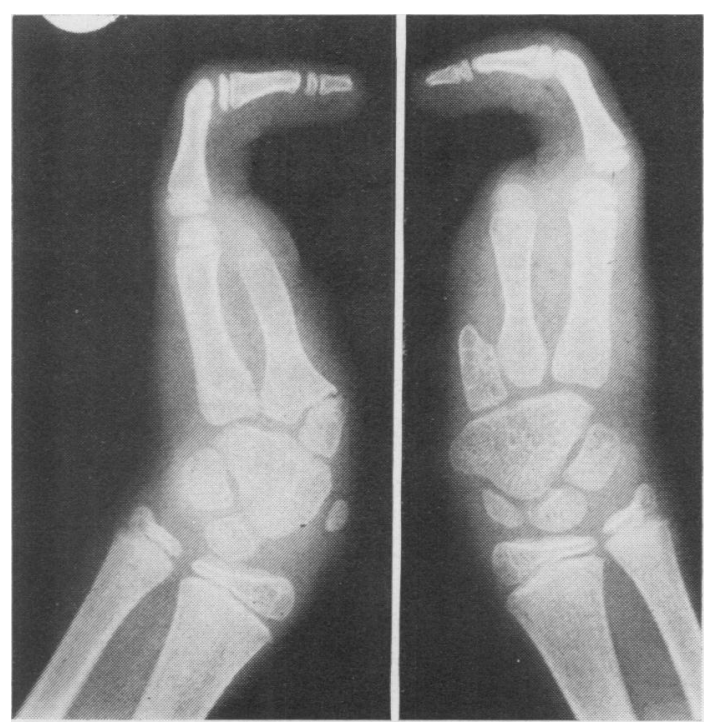

FIG. 4. Hand radiograph of III.6, family A. Note 2 parallel metacarpals in each hand. There is a fixed flexion deformity at the proximal interphalangeal joint.
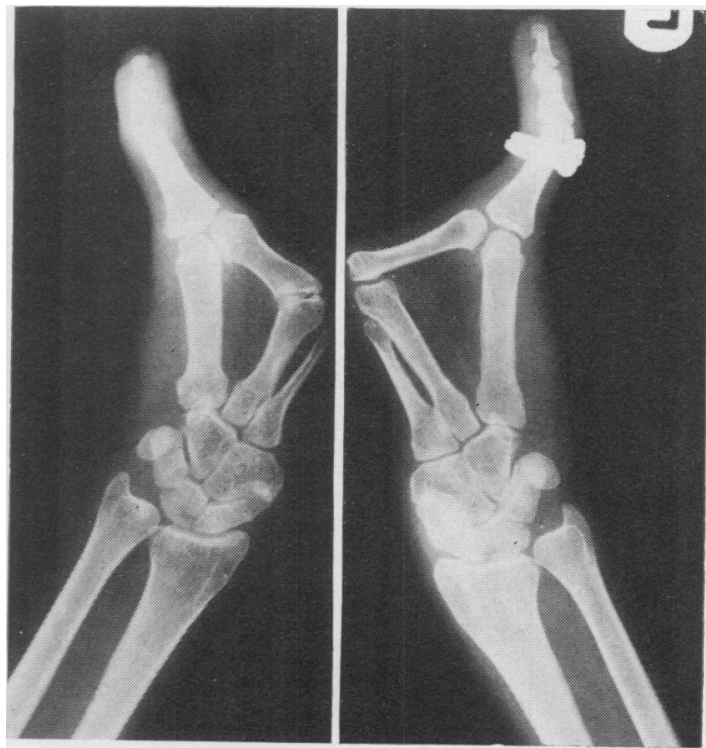

FIG. 5. Hand radiograph of II.4, family A. Note 2 parallel metacarpals in each hand with a rudimentary 3rd metacarpal, and a "crossbone' running between the distal ends of the 2 metacarpals and also articulates with the proximal phalanx. of the hands in most affected members, although IV.56 has monodactyly with a rudimentary second digit on both hands. The foot deformity was either simple monodactyly as in family A or cleft feet as in family B. In the second generation, the first generation to be affected, all 6 sibs were deformed.

\section{Discussion}

The outstanding feature of these families is that a condition subsequently inherited as an autosomal dominant with apparently complete penetrance appears first among more than one offspring of normal parents, who have no previous family history of ectrodactyly. Incomplete penetrance is not known to occur in type 1 dominant ectrodactyly, and there is no evidence to suggest that it has occurred in any of these families.

The probability of 2 (or 6 ) separate recurrent mutations occurring in each of the 3 families is so small that it can be disregarded. Another factor, that pater semper incertus est, cannot be completely excluded in pedigree A. However this is highly unlikely in pedigrees $\mathrm{B}$ and $\mathrm{C}$ where the family trees (including ancestors) were checked in parish marriage, baptism, and burial records.

The possibility that a single autosomal dominan 8 mutation under the epistatic effect of a second muo tant gene at a different locus protecting the carrief parent from developing the deformity, as has been postulated for familial total anomalous pulmonary venous return for example ( $\mathrm{Paz}$ and Castilla, 1971), is a possible mechanism which has been shown to exist in man in the Lewis blood group system and ABO secretor status (Grubb, 1951).

Delayed mutation, although it remains to be demonstrated in man, is a possibility. The original claim that it might have occurred in another family with ectrodactyly (Auerbach, 1955/1956) has not found support (Vogel, 1957/1958). Possibly the most likely explanation is that germinal mosaicism occurred in one of the parents in generation I. The de novo appearance of several mutant individuals in a family seems to be a phenomenon frequently noted in pedigrees of dominant ectrodactyly (Potter and Nadelhoffer, 1947; MacKenzie and Penrose, 1951/1952; Pillay, 1965; Phillips, 1971). Possibly germinal mosaicism may be a characteristic feature of type 1 dominant ectrodactyly. Alternatively, this condition, because of its very high penetrance, may be particularly favourable for its demonstration. In other conditions with reduced penetrance, it is impossible to distinguish the effects of incomplete penetrance and germinal mosaicism. 
Germinal mosaicism may have occurred in pedigrees of other human diseases. Aniridia congenita has been studied by Reed and Falls (1955), and they concluded that incomplete penetrance could not be ruled out and therefore that germinal mosaicism was 'unproven' in man. They included chondrodystrophy, neurofibromatosis, osteogenesis imperfecta, and retinoblastoma in their discussion and again invoked incomplete penetrance. The subject could be looked at another way, however, in that it is impossible to disprove germinal mosaicism in some pedigrees where incomplete penetrance is a possibility. Germinal mosaicism (with somatic mosaicism as well) for chromosome anomalies has been observed in humans. Normal women with more than one child with Down's syndrome have been found to have a trisomy 21 cell line in their lymphocytes or skin fibroblasts, and part or all of their oogonia are trisomic for chromosome 21 ; this type of gonosomic mosaicism has also been demonstrated in moles. It is known that developmental (Kosowicz et al, 1969) and also proliferative mosaicism occurs in sex chromosome anomalies, but its demonstration by 'breeding tests' is more difficult.

The parent with the mosaic gonad could have been of either sex in the families discussed above, and in all the reported pedigrees with germinal mosaicism and dominant ectrodactyly except in MacKenzie's and Penrose's pedigree B (1951/1952) where mosaicism if present must have been spermatogonial, and in Pillay's pedigree A (1965) where if present it must have been an oogonial mosaic. The existence of germinal mosaicism has been demonstrated in the house mouse (Dunn, 1934; Bhat, 1949; Falconer, 1951; Gruneberg, 1952; Dunn and Gluecksohn-Waelsch, 1953) the guinea pig (Wright and Eaton, 1926), and in Drosophila melanogaster (Bridges, 1919; Muller, 1920; Mohr, 1923; Morgan et al, 1925). Of these, the mosaic gonad must have been a testis in the 'short-tailed' mice of Morgan (1950) and in a spotted mouse of Dunn (1934). Both radiology and chemical mutagens have been reported to produce germinal mosaics artificially in Drosophila (Auerbach, 1946 and 1950).

In both family $A$ and $B$ the affected sibs in generation II were followed by one and two normal sibs respectively. It has been estimated by Hartl (1971) that if more than one child in the sibship is affected, and one of the parents is a presumptive germinal mosaic, then the risk to subsequent offspring varies from $20 \%$ to $35 \%$ depending upon the number of normal children in the sibship already. This estimate is based on several assumptions: (1) that the mutation rate per cell generation is constant, (2) that there is no cell selection, and (3) that germ cells divide synchronously so that both normal and abnormal cells have an identical generation time. However it is evident that the risk in practice may be very different from the empirical figures above (MacKenzie and Penrose, 1951/1952). Also it may be significant that in both pedigrees $A$ and $B$ the normal sibs appeared after the affected ones.

Along the 'production line' hypothesis (Henderson and Edwards, 1968) oocytes formed early in the fetal ovary are ovulated early in life. In this situation, if mutation occurred in a germ cell precursor during development, then the mutant ova shed may come in clusters. In pedigrees $A$ and $B$ the order would be normal ova until sometime before the first pregnancy, followed by ova with the mutated locus resulting in the affected offspring, followed by normal ova resulting in normal offspring. Following instead the 'cell selection' theory (Taylor, 1968), there would perhaps be selection against the ova with the mutant locus so that ova shed later would be more likely to be normal.

\section{Summary}

Three new pedigrees of dominant ectrodactyly are reported. All 3 show the de novo appearance of several mutant individuals in the first affected generation. Incomplete penetrance can be excluded, and the possible explanations are germinal mosaicism, delayed mutation, and a single autosomal dominant gene mutation under the epistatic effect of a second mutant gene at a separate locus protecting the carrier parents from having the deformity. This particular type of dominant ectrodactyly may be especially favourable for the detection of any of these events, and germinal mosaicism is thought to be the most likely explanation of these pedigrees.

I am indebted to Professor P. E. Polani for his advice and comments on the manuscript, to Dr J. Jancar and Dr U. Wolf for their help, to Mr E. Mervyn Evans for permission to publish the radiographs, and to the general practitioners and others who helped to contact members of the families. The author is supported by grants from the South Western Regional Hospital Board and the United Bristol Hospitals.

\section{REFERENCES}

Auerbach, C. (1946). Chemically induced mosaicism in Drosophila melanogaster. Proceedings of the Royal Society of Edinburgh, Section $B$ (Biology), 62, 211-222.

Auerbach, C. (1950). Differences between effects of chemical and physical mutagens. Publicazioni della Stazione Zoologica di Napoli, Suppl., 22, 1-19.

Auerbach, C. (1955/1956). A possible case of delayed mutation in man. Annals of Human Genetics, 20, 266-269. 
Bhat, N. R. (1949). A dominant mutant mosaic house mouse. Heredity, 3, 243-248.

Bridges, C. B. (1919). The developmental stages at which mutations occur in the germ tract. Proceedings of the Society of Experimental Biology and Medicine, 17, 1-2.

Dunn, L. C. (1934). Analysis of a case of mosaicism in the housemouse. Fournal of Genetics, 29, 317-326.

Dunn, L. C. and Gluecksohn-Waelsch, S. (1953). Genetic analysis of seven newly discovered mutant alleles at locus $\mathrm{T}$ in the house mouse. Genetics, 38, 261-271.

Falconer, D. S. (1951). Two new mutants, 'trembler' and 'reeler' with neurological actions in the house mouse. Fournal of Genetics, 50, 192-201.

Freire-Maia, A. (1971). A recessive form of ectrodactyly, and its implications in genetic counseling. Fournal of Heredity, 62, 53.

Grubb, R. (1951). Observations on the human group system Lewis. Acta Pathologica et Microbiologica Scandinavica, 28, 61-81.

Gruneberg, H. (1952). The Genetics of the Mouse. Martinus Niihoff, The Hague.

Hartl, D. L. (1971). Recurrence risks for germinal mosaics. American fournal of Human Genetics, 23, 124-134.

Henderson, S. A. and Edwards, R. G. (1968). Chiasma frequency and maternal age in mammals. Nature, 218, 22-28.

Kosowicz, J., Bialecki, M., Wojtowicz, M., and Sobieszczyk, S. (1969). Unilateral gonadal dysgenesis. American fournal of Obstetrics and Gynecology, 105, 1116-1123.

Lewis, T. (1909). Hereditary malformations of the hands and feet; hereditary split foot. In Treasury of Human Inheritance, ed. by W. Bullock, T. Lewis, W. C. Rivers, and J. Horne. Vol. 1. Part I-II, pp. 6-10. Cambridge University Press, London.
MacKenzie, H. J. and Penrose, L. S. (1951/1952). Two pedigrees of ectrodactyly. Annals of Eugenics, 16, 88-96.

Mohr, O. L. (1923). A somatic mutation in the singed locus of the C-chromosome in Drosophila melanogaster. Hereditas, Genetiskt Arkiv, 4, 142-160.

Morgan, T. H., Bridges, C. B., and Sturtevant, A. H. (1925). The Genetics of Drosophila. Martinus Nijhoff, The Hague.

Morgan, W. C. (1950). A new tail-short mutation in the mouse. fournal of Heredity, 41, 208-215.

Muller, H. J. (1920). Further changes in the white-eye series of Drosophila and their bearing on the manner of occurrence of mutation. fournal of Experimental Zoology, 31, 443-473.

Paz, J. E. and Castilla, E. E. (1971). Familial total anomalous pulmonary venous return. Fournal of Medical Genetics, 8, 312-314.

Phillips, R. S. (1971). Congenital split foot (lobster claw) and triphalangeal thumb. Fournal of Bone and foint Surgery, 53B, 247257.

Pillay, V. K. (1965). Ectrodactyly. Singapore Medical fournal, 6, 110-115.

Potter, E. L. and Nadelhoffer, L. (1947). A familial lobster-claw. fournal of Hereditary, 38, 331-335.

Reed, T. E. and Falls, H. F. (1955). A pedigree of aniridia with a discussion of germinal mosaicism in man. American fournal of Human Genetics, 7, 28-38.

Taylor, A. I. (1968), Cell selection in vivo in normal/G trisomic mosaics. Nature, 219, 1028-1030.

Vogel, F. (1957/1958). Verzögerte Mutation beim Menschen? Annals of Human Genetics, 22, 132-137.

Wright, S. and Eaton, O. N. (1926). Mutational mosaic coat patterns of the guinea pig. Genetics, 11, 333-351. 